\title{
Inhibition of notch signaling pathway prevents cholestatic liver fibrosis by decreasing the differentiation of hepatic progenitor cells into cholangiocytes
}

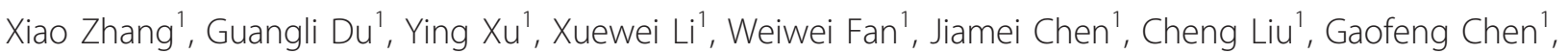 \\ Chenghai Liu', Mark A Zern², Yongping Mu and Ping Liu'
}

\begin{abstract}
Although hepatic progenitor cells (HPCs) are known to contribute to cholestatic liver fibrosis (CLF), how Notch signaling modulates the differentiation of HPCs to cholangiocytes in CLF is unknown. Thus, using a rat model of CLF that is induced by bile duct ligation, we inhibited Notch signaling with DAPT. In vivo, CK19, OV6, Sox9, and EpCAM expression was increased significantly. Notch signaling increased after bile duct ligation, and DAPT treatment reduced the expression of CK19, OV6, Sox9, and EpCAM and blocked cholangiocyte proliferation and CLF. In vitro, treatment of a WB-F344 cell line with sodium butyrate resulted in increased mRNA and protein expression of CK19, Sox9, and EpCAM, but Notch signaling was activated. Both of these processes were inhibited by DAPT. This study reveals that Notch signaling activation is required for HPC differentiation into cholangiocytes in CLF, and inhibition of the Notch signaling pathway may offer a therapeutic approach for treating CLF.
\end{abstract}

Laboratory Investigation (2016) 96, 350-360; doi:10.1038/labinvest.2015.149; published online 21 December 2015

Cholestasis is associated with several chronic liver diseases, such as biliary atresia, primary biliary cirrhosis, and primary sclerosing cholangitis, which can cause hepatocellular injury, fibrosis, and cirrhosis. ${ }^{1}$ Activation of biliary proliferation is thought to contribute to the initiation and progression of cholestatic liver fibrosis (CLF). Specifically, proliferating cholangiocytes have been shown to secrete platelet-derived growth factor $\mathrm{B}$, transforming growth factor (TGF)- $\beta 1$, monocyte chemotactic protein (MCP)-1, and connective tissue growth factor to stimulate the activation, migration, and proliferation of hepatic stellate cells (HSCs) and fibroblasts, leading to the excessive generation of extracellular matrix (ECM) and fibrotic progression. ${ }^{2-5}$ These findings suggest that cholangiocyte proliferation is critical to the formation of CLF. Thus, inhibition of abnormal biliary epithelial cells (BECs) activation and proliferation may reverse biliary fibrosis, partially or even completely. ${ }^{6}$ Until recently, no therapy effectively inhibited abnormal BECs activation. Ursodeoxycholic acid (UDCA) was shown to improve survival of patients with advanced primary biliary cirrhosis, but as many as $40 \%$ of patients do not respond satisfactorily to UDCA therapy and adjunctive therapies are needed. ${ }^{7}$

In recent years, Notch signaling has been demonstrated to be involved in the process of bile duct proliferation. ${ }^{8,9}$ In mammals, Notch signaling includes four receptors (Notch-1, $2,3,4)$ and two families of ligands (Jagged and Delta-like). Notch receptor activation is irreversible as it involves proteolysis-mediated release of the Notch intracellular domain (NICD), translocation to the nucleus, and association with a DNA-bound protein. ${ }^{10}$ Notch signaling ablation results in the failure of hepatoblast specification into cholangiocytes and bile duct paucity ${ }^{11,12}$ which is a characteristic of Alagilles syndrome. ${ }^{13,14}$ However, ectopic activation of Notch signaling in fetal hepatoblasts by the overexpression of NICD results in hyperarborization of biliary ductules. ${ }^{15}$ Notch signaling also regulates tubular morphogenesis during the DDC- or ANIT-induced biliary wound-healing process in mice. ${ }^{8}$ In addition, multiple investigators have reported that the adult liver contains bipotential progenitor cells, which can proliferate and differentiate toward either hepatocyte or cholangiocyte lineages in vivo and in vitro. ${ }^{16}$ However, the relationship among CLF, the Notch signaling pathway, and hepatic

\footnotetext{
Shuguang Hospital Affiliated to Shanghai University of Traditional Chinese Medicine; Institute of Liver Diseases, Shanghai University of Traditional Chinese Medicine, Shanghai, China and 'Department of Internal Medicine, Institute for Regenerative Cures, University of California Davis Medical Center, Sacramento, CA, USA

Correspondence: Professor Y Mu, MD, PhD or P Liu, MD, PhD, Shuguang Hospital Affiliated to Shanghai University of Traditional Chinese Medicine; Institute of Liver Diseases, Shanghai University of Traditional Chinese Medicine, 528, Zhangheng Road, Pudong district, Shanghai 201203, China.

E-mail: ypmu8888@126.com or Liuliver@vip.sina.com
}

Received 7 June 2015; revised 23 August 2015; accepted 28 August 2015 
progenitor cell (HPCs) are unclear. In this work, we observed that inhibition of the Notch signaling pathway prevented CLF, and that this occurs through decreased differentiation of HPCs into cholangiocytes.

\section{MATERIALS AND METHODS Materials}

Mouse monoclonal antibody to $\alpha$-smooth muscle actin ( $\alpha$-SMA, Clone 1A4) was obtained from Sigma-Aldrich (St Louis, MO, USA). Rabbit polyclonal antibody to CK19 (Cat:10712-1-AP) was purchased from Proteintech (Chicago, IL, USA). Mouse monoclonal antibody to OV6 (Cat: MAB2020) was purchased from R\&D Systems (Minneapolis, MN, USA). Rabbit monoclonal antibodies to Notch-1 (D6F11) and Notch-2 (D67C8) were purchased from cell signaling (Beverly, MA, USA). Rabbit monoclonal antibodies to Notch3 (ab178948), RВPJK (ab180588) and rabbit polyclonal antibody to Numb (ab14140) were obtained from Abcam (Cambridge, MA, USA). Rabbit polyclonal antibodies to Notch4 (sc-5594), JAG1 (sc-8303), DLL1 (sc-9102), mouse monoclonal antibody to Sox9 (E-9, sc-166505), and goat polyclonal antibody to JAG2 (sc-34475) were purchased from Santa Cruz Biotechnology (Santa Cruz, CA, USA). Mouse monoclonal antibody to glyceraldehyde-3-phosphate dehydrogenase (GAPDH) was obtained from Chemicon International (Temecula, CA, USA). Horseradish peroxidase (HRP)-conjugated polyclonal rabbit anti-mouse immunoglobulins, HRP-conjugated polyclonal swine anti-rabbit immunoglobulins were obtained from Dako Denmark A/S. Hybond-ECL nitrocellulose membranes and ECL detection reagent were obtained from Amersham Pharmacia Biotech (Buckinghamshire, UK). All other reagents were purchased from Sigma Chemical or Wako Pure Chemical.

\section{Animals and Experimental Protocol}

Sprague-Dawley rats (7-8 weeks-of-age) were obtained from the Shanghai Experimental Animal Center of the Chinese Academy of Sciences (Shanghai, China). Animals were housed at a constant temperature and supplied with laboratory chow and water ad libitum. The experimental protocol was approved by the Animal Research Committee of Shanghai University of Traditional Chinese Medicine (Guide for Animal Experiments, Shanghai University of Traditional Chinese Medicine).

Bile duct ligation (BDL) was performed as previously described ${ }^{17}$ with modifications. In brief, 38 male s.d. rats were randomly divided into sham $(n=6)$ or model groups $(n=32)$. Model rats were anesthetized with pentobarbital sodium and laparotomy was performed with a sterile technique. The common bile duct and the left and right hepatic ducts were isolated. The left and right hepatic ducts and the hepatic portal and duodenal site of the common bile duct were ligated, respectively, and the abdomen was closed. In sham rats, the surgery was identical, except that the bile duct was not ligated.
At the end of the first, second, third and fourth weeks, eight rats were killed under $2 \%$ pentobarbital sodium anesthesia, respectively, and the portal vein was cannulated using an 18-G Teflon catheter. Blood was collected from the inferior vena cava, and centrifuged at $3000 \mathrm{rpm}$ for $30 \mathrm{~min}$ at $4{ }^{\circ} \mathrm{C}$. Sera were stored at $-70^{\circ} \mathrm{C}$. Livers were perfused with $100 \mathrm{ml}$ PBS ( $\mathrm{pH} 7.0$ ) to remove blood. A small portion of the liver was fixed with $4 \%$ paraformaldehyde, embedded in paraffin, and frozen. Another portion of the liver was fixed with OCT and snap-frozen in liquid nitrogen, then stored at $-70{ }^{\circ} \mathrm{C}$ until reverse transcription-PCR (RT-PCR) and immunoblotting.

\section{Notch Signaling Pathway Block}

Twenty-six rats were randomly divided among the BDL group $(n=10)$, the DAPT (GSI-IX, a prototypical gamma-secretase inhibitor, and inhibiting gamma-secretase can prevent Notch receptor cleavage and thereby block Notch signal transduction) group $(n=10)$, and a sham group $(n=6)$. The BDL and DAPT groups had bile duct ligation as previously described. DAPT (Sigma-Aldrich) was injected (ip, $50 \mathrm{mg} / \mathrm{kg}$ ). Sham rats were given DMSO (equal volume, ip). At the end of the second week, rats were killed and organs were harvested as described.

\section{Serum Chemistries}

Serum alanine aminotransferase (ALT), aspartate aminotransferase (AST), gamma-glutamyl transferase (GGT), alkaline phosphatase (ALP), and total bilirubin (TBil) were measured using standard laboratory methods.

\section{Hepatic Hydroxyproline Content}

Hepatic hydroxyproline (HYP) was measured using a modified version of the method of Jamall's group. ${ }^{18}$ In brief, liver samples were homogenized and hydrolyzed in $6 \mathrm{~N} \mathrm{HCl}$ at $110^{\circ} \mathrm{C}$ for $18 \mathrm{~h}$. After filtration of the hydrolysate through a 0.45-mm Millipore filter (Millipore, Bedford, MA, USA), chloramine $\mathrm{T}$ was added (final concentration $2.5 \mathrm{mM}$ ). The mixture was then treated with $410 \mathrm{mM}$ paradigm ethylamino-benzaldehyde and incubated at $60{ }^{\circ} \mathrm{C}$ for $30 \mathrm{~min}$. After cooling to room temperature, samples were read at $560 \mathrm{~nm}$ against a reagent blank, which contained the complete system without added tissue. HYP was quantified from a standard (Nakateyitesuku Company, Japan).

\section{Histochemical and Immunohistochemical Analyses of Rat Livers}

Paraformaldehyde-fixed specimens were cut into 4 - $\mu$ m-thick sections and stained with $0.1 \%(\mathrm{w} / \mathrm{v})$ Sirius Red (Direct Red 80; Aldrich, Milwaukee, WI, USA), or hematoxylin and eosin (H\&E). Immunostaining was performed according to previously published methods. ${ }^{19}$ In brief, sections were deparaffinized, washed, and preincubated in blocking solution, followed by incubation with anti- $\alpha$-SMA (1:200), CK19 (1:100), OV6 (1:40), Sox9 (1:400) antibodies. Sections were then incubated with HRP-conjugated secondary antibodies 
Table 1 Primer pairs and probes used for real-time PCR

\begin{tabular}{|c|c|c|c|c|c|}
\hline Primer name & Sequence & Note & Primer name & Sequence & Note \\
\hline TNF-a & & TaqMan & Notch-2 & & TaqMan \\
\hline Forward & 5'-GCTCCCTCTCATCAGTTCCATG-3' & & Forward & 5'-GAGGAAGAAGTGTCTCAA-3' & \\
\hline Reverse & 5'-TACGGGCTTGTCACTCGAGTITG-3' & & Reverse & 5'-GTGGCATCAGAAACATATG-3' & \\
\hline \multirow[t]{2}{*}{ Probe } & 5'-CCCAGACCCTCACACTCAGATCATCTTC-3' & & Probe & 5'-AGAAGGTCCAGCTCTCCGAGA-3' & \\
\hline & & & Notch3 & & SYBR \\
\hline TGF- $\beta 1$ & & TaqMan & Forward & 5'-GACAAGGACCACTCCCACTACT-3' & \\
\hline Forward & 5'-TGCTTCCGCATCACCGT-3' & & Reverse & 5'-ATCCACATCATCCTCACAACTG-3' & \\
\hline Reverse & 5'-TAGTAGACGATGGGCAGTGGC-3' & & & & \\
\hline \multirow[t]{2}{*}{ Probe } & 5'-CTGCGTGCCGCAGGCTTGG-3' & & Notch4 & & SYBR \\
\hline & & & Forward & $5^{\prime}$-TGTCAGGAACCAGTGTCAGAAC-3' & \\
\hline$a-S M A$ & & TaqMan & Reverse & 5'-CCTGGGCTTCACATTCATCTAT-3' & \\
\hline Forward & 5'-GAGGAGCATCCGACCTTGC-3' & & & & \\
\hline Reverse & 5'-TTTCTCCCGGTTGGCCTTA-3' & & $J A G 1$ & & TaqMan \\
\hline \multirow[t]{2}{*}{ Probe } & 5'-AACGGAGGCGCCGCTGAACC-3' & & Forward & $5^{\prime}$-CCATCAAGGATTATGAGAAC-3' & \\
\hline & & & Reverse & 5'-TGGTGCTTATCCATATCA-3' & \\
\hline $\operatorname{Col}(1)$ & & TaqMan & Probe & 5'-CTCTTCCACTTCCGAGTTGTGT-3' & \\
\hline Forward & 5'-GCCTCCCAGAACATCACCTA-3' & & & & \\
\hline Reverse & 5'-CCTTCTTGAGGTTGCCAGTC-3' & & $J A G 2$ & & SYBR \\
\hline \multirow[t]{2}{*}{ Probe } & 5'-AAGAACAGCGTGGCCTACAT-3' & & Forward & 5'-AAATGAGTGGTCCGTGGCAGA-3' & \\
\hline & & & Reverse & 5'-TGGTTGGAAGCCTTGTCTGCT-3' & \\
\hline $\mathrm{Col}(4)$ & & TaqMan & & & \\
\hline Forward & 5'-GAGAGAGGCTTCCCTGGTCT-3' & & DLL1 & & SYBR \\
\hline Reverse & 5'-ACTTGCTCCAGAGGGACCTT-3' & & Forward & 5'-GTGTGCAGATGGTCCTTGCTTC-3' & \\
\hline Probe & 5'-TCTGGTGAACCTGGCAAAC-3' & & Reverse & 5'-CTGACATCGGCACAGGTAGGAG-3' & \\
\hline$M C P-1$ & & SYBR & DLL3 & & SYBR \\
\hline Forward & 5'-TGTCTGGACCCATTCCTTCT-3' & & Forward & 5'-CTGAGGTTACAAGACGGTGCT-3' & \\
\hline Reverse & 5'-ACCAGCAAGATGATCCCAAT-3' & & Reverse & 5'-GTAAATGGAAGGGCTGGTATG-3' & \\
\hline CK19 & & SYBR & DLL4 & & SYBR \\
\hline Forward & 5'-TATCTGGATCTGCGTAGTGTGG-3' & & Forward & 5'-GCAGAACCACACACTGGACTA T-3' & \\
\hline Reverse & 5'-ATACAAAACCAAACTGGGGATG-3' & & Reverse & 5'-TGGCACCTTCTCTCCTAAACTC-3' & \\
\hline OV6 & & SYBR & Hes1 & & SYBR \\
\hline Forward & 5'-GATGCTGGACACAAACTCAACT3' & & Forward & 5'-GACGGCCAATTTGCTITC-3' & \\
\hline Reverse & 5'-GCCACAACAGGAATCTCTCC-3' & & Reverse & 5'-GACACTGCGTTAGGACCC-3' & \\
\hline Sox9 & & SYBR & $R B P-J \mathrm{~K}$ & & SYBR \\
\hline Forward & 5'-GAAAGACCACCCCGATTACAAG-3' & & Forward & 5'-TTGCTTACCTTCAGGCGTGTG-3' & \\
\hline Reverse & 5'-AAGATGGCGTTAGGAGAGATGTG-3' & & Reverse & 5'-GCCCAATGAGTCTGCTGCAA-3' & \\
\hline EpCAM & & SYBR & Numb & & SYBR \\
\hline Forward & 5'-TGTGGACATAGCTGATGTGGCTTAC-3' & & Forward & 5'-GCTACTITCGATGCCAGTAGAACCA-3' & \\
\hline Reverse & 5'-CACCCTCAGGTCCATGCTCTTA-3' & & Reverse & 5'-CTGTTGCCAGGAGCCACTGA-3' & \\
\hline Notch-1 & & SYBR & GAPDH & & SYBR \\
\hline Forward & 5'-TGGATGAGGAAGACAAGCATTA-3' & & Forward & 5'-GGCACAGTCAAGGCTGAGAATG-3' & \\
\hline Reverse & 5'-GAAAAGCCACCGAGATAGTCAG-3' & & Reverse & 5'-ATGGTGGTGAAGACGCCAGTA-3' & \\
\hline
\end{tabular}

Table 1 Continued

Forward 5'-AAATGAGTGGTCCGTGGCAGA-3' BR 
Table 1 Continued

\begin{tabular}{llc}
\hline Primer name & Sequence & Note \\
\hline GAPDH & & TaqMan \\
Forward & 5'-AAGATGGTGAAGGTCGGTGTG-3' & \\
Reverse & 5'-GAAGGCAGCCCTGGTAACC-3' & \\
Probe & 5'-CGGATTGGCCGTATCGGACGC-3' \\
\hline
\end{tabular}

(1:1000), washed, covered with DAB, and counterstained with hematoxylin. A Leica SCN 400 was used to visualize samples.

For immunofluorescent staining, Alexa fluor 488 and cyanine 3 secondary antibodies (Jackson ImmunoResearch, West Grove, PA, USA) were used with counterstaining. Images were obtained under a confocal laser scanning microscope FV10i (Olympus, Japan).

\section{Immunoblot Analysis}

Liver tissue was lysed in RIPA buffer containing $50 \mathrm{mM}$ Tris- $\mathrm{HCl}(\mathrm{pH}$ 7.2), $150 \mathrm{mM} \mathrm{NaCl}, 1 \% \mathrm{NP}-40,0.1 \%$ SDS, $1 \mathrm{mM}$ EDTA, and $1 \mathrm{mM}$ PMSF and then homogenized in ice-cold water. After centrifugation for $10 \mathrm{~min}$ at $4{ }^{\circ} \mathrm{C}$ at $12000 \mathrm{rpm}$, protein was measured using a Bio-Rad Dc protein Assay Reagent (Bio-Rad, Hercules, CA, USA). Protein was electrophoretically resolved with 10 or $12 \%$ SDS-PAGE, and successively transferred to Hybond-ECL nitrocellulose membranes. Membranes were blocked with 5\% non-fat dietary milk solution in Tris-buffered saline $(20 \mathrm{mM}$ Tris and $150 \mathrm{mM} \mathrm{NaCl}, \mathrm{pH} 7.4$ ) with $0.1 \%$ Tween-20. Membranes were incubated overnight with primary antibodies at $4{ }^{\circ} \mathrm{C}$ and successively with secondary antibodies at room temperature for $1 \mathrm{~h}$. The following dilutions of primary antibodies were used: $\alpha$-SMA, 1:200; CK19, 1:200; OV6, 1:200; Sox9, 1:2000; Notch-1, 1:1000; Notch-2, 1:1000; Notch3, 1:2000; Notch4, 1:200; JAG1, 1:200; JAG2, 1:200; DLL1, 1:200; RВРЈк,1:2,000; Numb, 0.5 g/ml; GAPDH, 1:30 000. Immune complexes were visualized using a SuperSignal West Pico Chemiluminescent Substrate (ECL, Pierce, Rockford, IL, USA). Finally, band intensity was measured using scanning video densitometry.

\section{RNA Preparation and Quantitative Real-Time RT-PCR}

mRNA expression of tumor necrosis factor-alpha (TNF- $\alpha$ ), TGF- $\beta 1, \alpha$-SMA, Col(1), Col(4), MCP-1, CK19, OV6, Sox9, EpCAM, Notch-1,-2,-3,-4, JAG1,-2, DLL1, RBPJK, and Numb were quantified with quantitative RT-PCR. Total RNA was extracted from liver tissues using total RNA purification kit (Lot. 250800) (TOYOBO, Osaka, Japan). mRNA expression was measured using Real-time PCR Master Mix (TaqMan) (Lot. 056700) or SYBR Green Real-time PCR Master Mix (TaqMan) (Lot. 411900) (TOYOBO), and the ViiA 7 RealTime PCR System (ABI, American) was used. Primers and oligonucleotide probes were designed using Primer Express
(Takara Chemical), and are listed in Table 1. Each PCR amplification was performed on five rats in both experimental and control groups. Individual gene expression was normalized to GAPDH. Conditions for the TaqMan One-Step RT-PCR were as follows: $30 \mathrm{~min}$ at $48{ }^{\circ} \mathrm{C}$ (stage 1, RT), 10 min at $95{ }^{\circ} \mathrm{C}$ (stage 2, RT inactivation and Ampli Taq Gold activation), and then 40 cycles of amplification for $15 \mathrm{~s}$ at $95^{\circ} \mathrm{C}$ and $1 \mathrm{~min}$ at $60^{\circ} \mathrm{C}$ (stage $3, \mathrm{PCR}$ ). Conditions for the One-Step SYBR RT-PCR (Perfect Real Time) were as follows: an initial step of $15 \mathrm{~min}$ at $42^{\circ} \mathrm{C}, 2 \mathrm{~min}$ at $95^{\circ} \mathrm{C}$, and then 40 amplification cycles of denaturation at $95^{\circ} \mathrm{C}$, for $15 \mathrm{~s}$, and annealing and extension at $60^{\circ} \mathrm{C}$ for $1 \mathrm{~min}$.

\section{WB-F344 Cell Line Culture and Treatment}

In vitro studies were performed in WB-F344 cell lines, which have morphological and functional characteristics similar to those of freshly isolated HPCs. ${ }^{20}$ Cells were cultured at $37^{\circ} \mathrm{C}$ in a $5 \% \mathrm{CO}_{2}$ in air atmosphere in Ham's $\mathrm{F} 12$ medium (Life Technologies) supplemented with $10 \%$ fetal calf serum (Life Technologies). Chemically induced differentiation was obtained by culturing WB-F344 cells on six-well Permanox Lab-Tek culture slides (NalgeNunc International, Naperville) at a density of $2 \times 10^{3}$ cells $/ \mathrm{cm}^{2}$, starting $24 \mathrm{~h}$ after seeding. Cells were divided into control group (C), SB group $\left(3.75 \mathrm{mM}\right.$, Sigma, B5887-1G) ${ }^{21}$ and SB plus DAPT $(50 \mu \mathrm{M})$ group ( $n=3$, respectively). Media was exchanged every 2 days, and the culture time was 7 days.

\section{Statistical Analysis}

All results are expressed as mean \pm s.d.; statistical analysis was performed using one-way ANOVA with SPSS10.0 software. $P<0.05$ was considered to be statistically significant.

\section{RESULTS}

Pathological Changes in CLF Induced by BDL

H\&E staining showed that bile duct proliferation gradually increased accompanied by inflammatory cell infiltration in the BDL group (Figure 1a). Sirius red staining revealed that proliferated bile duct cells were surrounded by abundant collagen in the BDL group (Figure 1b). Immunostaining also confirmed $\alpha$-SMA expression (myofibroblast (MF) marker) surrounded proliferated bile duct cells (Figure 1c).

ALT, AST, ALP, GGT activity, and serum TBil gradually increased (Figure 1d) and hepatic HYP was mildly elevated in the first week, increasing significantly from the second week and onward $(P<0.01$, Figure 1e). In addition, consistent with changes in liver pathology, TNF- $\alpha$, TGF- $\beta 1$, MCP- $1, \alpha$-SMA, $\mathrm{Col}(1)$, and $\mathrm{Col}(4)$ mRNA gradually increased (Figure 1f).

\section{HPCs Are a Source of Proliferated Cholangiocytes}

Ki67 immunostaining indicates no cholangiocyte proliferation in the sham group, and that the progress of cholestasis, cholangiocyte proliferation increased gradually in bile duct reaction (Supplementary Fig 1). CK19 is a marker of bile epithelial cells ${ }^{22}$ and OV6 is an antigen-specific for rodent 
a

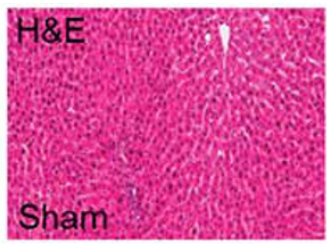

b

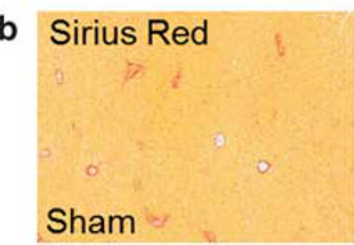

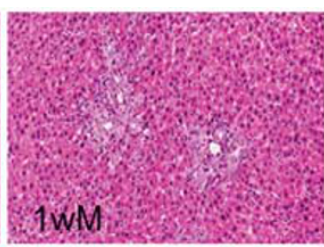
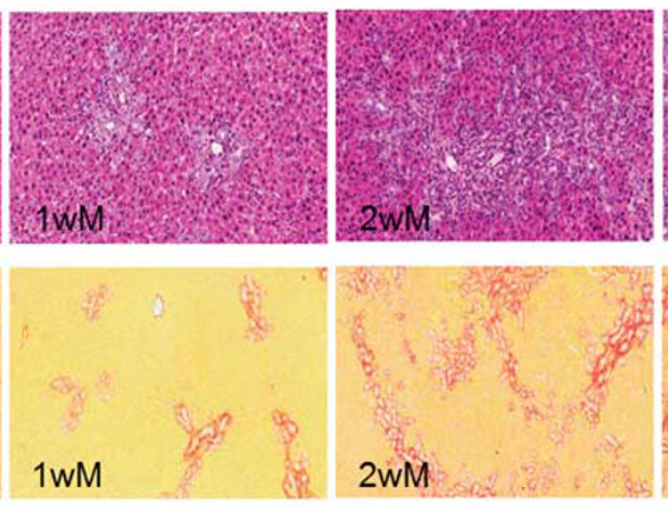
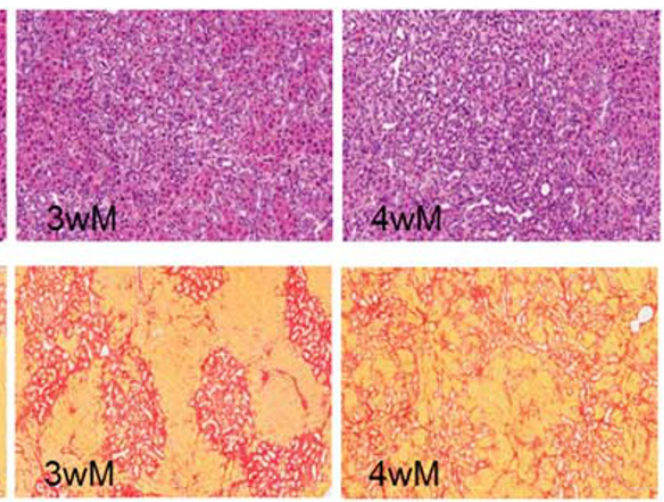

C
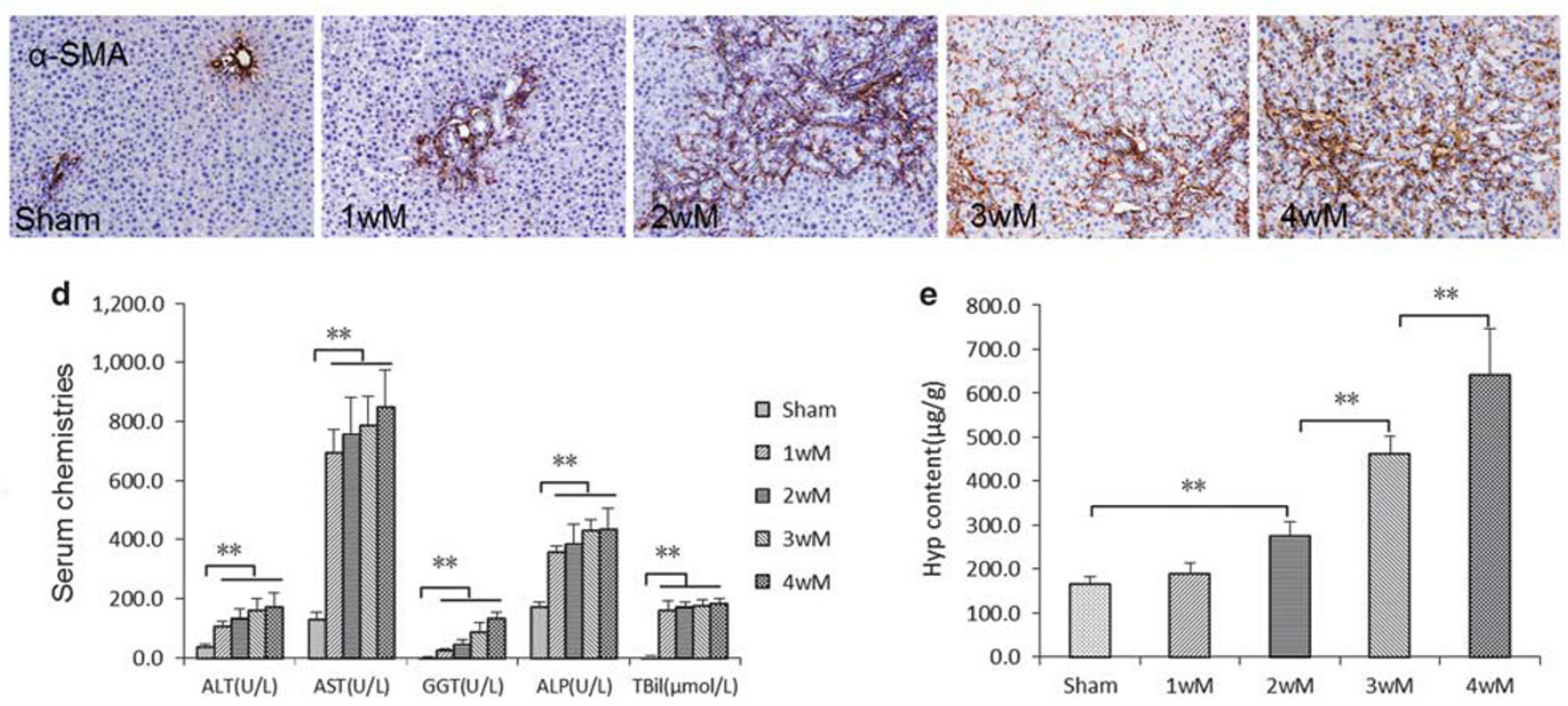

f

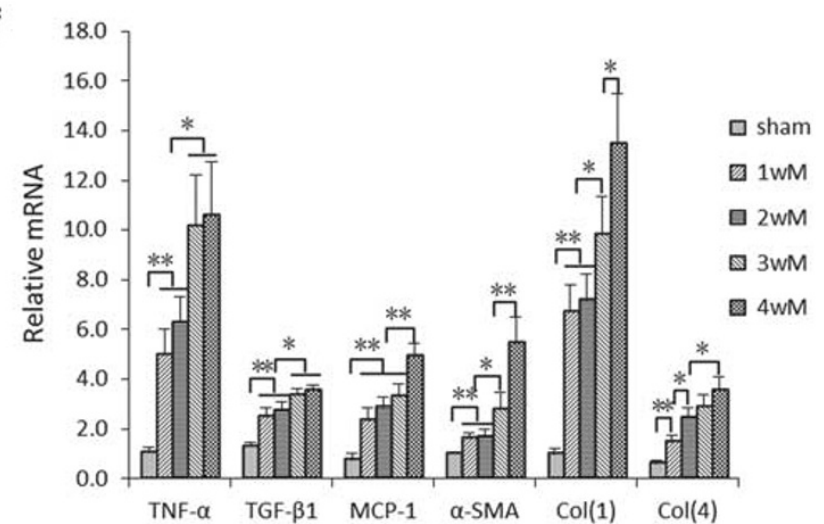

Figure 1 Pathological changes in CLF induced by BDL. (a) H\&E staining $(\times 200)$. (b) Sirius Red staining $(\times 100)$. (c) $a$-SMA immunostaining $(\times 200)$. (d) Serum chemistries. (e) Hepatic hydroxyproline content. (f) TNF- $a$, TGF- $\beta$ MCP-1, $a$-SMA, Col(1), and Col(4) mRNA were measured by RT-PCR and normalized to GAPDH mRNA ( $n=6$ per group). ${ }^{*} P<0.05$, ${ }^{*} P<0.01$. sham, sham group; $1 \mathrm{wM}, \mathrm{BDL}-1 \mathrm{w}$ group; $2 \mathrm{wM}, \mathrm{BDL}-2 \mathrm{w}$ group; 3 wM, BDL-3w group; 4 wM, BDL-4w group.

hepatic stem cells. ${ }^{23}$ Sox9 is an endodermal transcription factor, and EpCAM is a stem/progenitor cell surface marker. ${ }^{24-26}$ Immunostaining showed that CK19 and OV6 were expressed in proliferated cholangiocytes after BDL treatment (Figures 2a and b). Co-immunostaining revealed that OV6/CK19, Sox9/CK19 were extensively co-expressed in proliferated cholangiocytes (Figures $2 \mathrm{c}$ and $\mathrm{d}$ ) and immunoblotting confirmed CK19, OV6, Sox9, and EpCAM protein gradually increased (Figure 2e). Consistent with these data, CK19, OV6, Sox9, and EpCAM mRNA increased significantly, and were statistically significantly different among the various time points $(P<0.01$, Figure $2 \mathrm{f})$. 
a

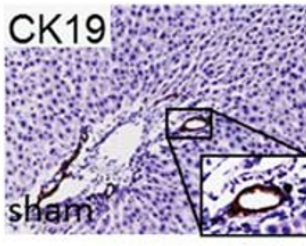

b

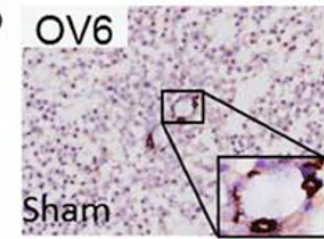

c

\section{ov6/CK19}

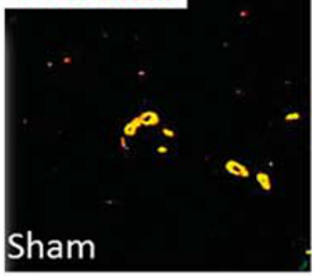

d

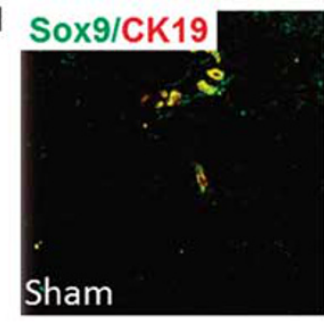

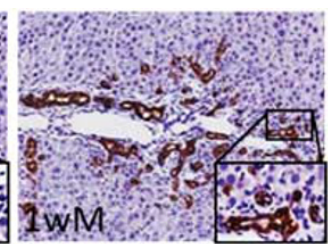
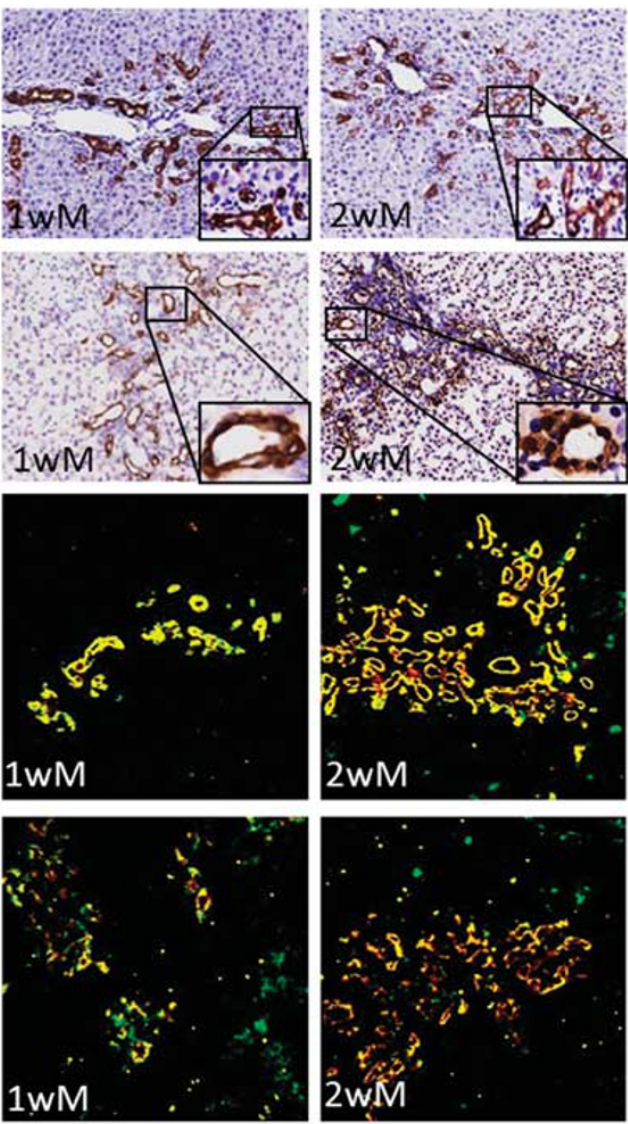
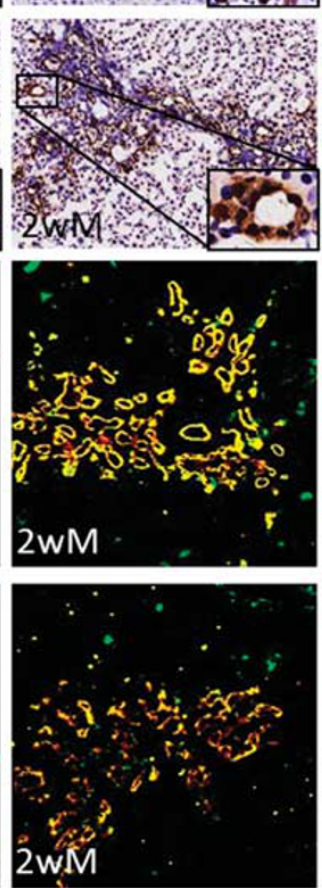
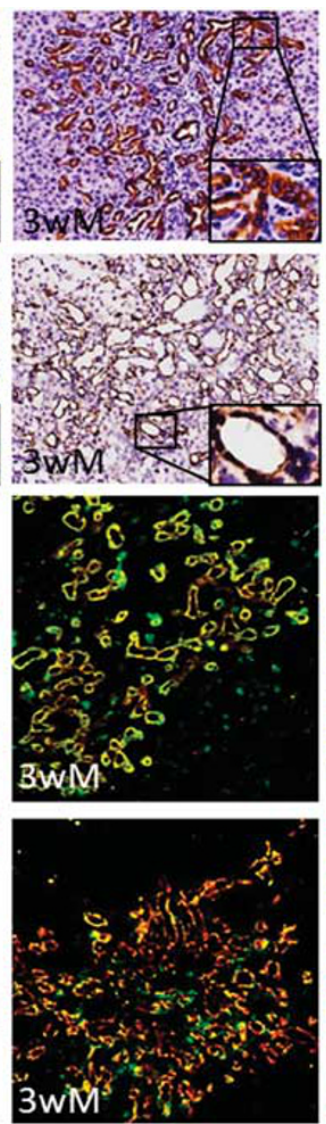
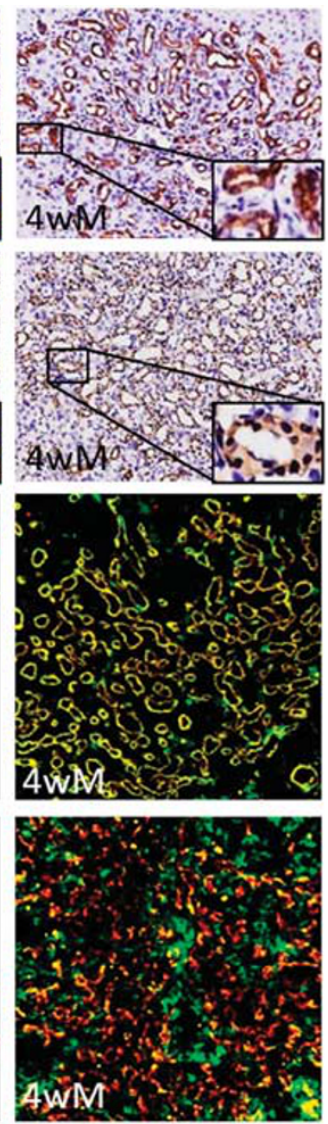

e
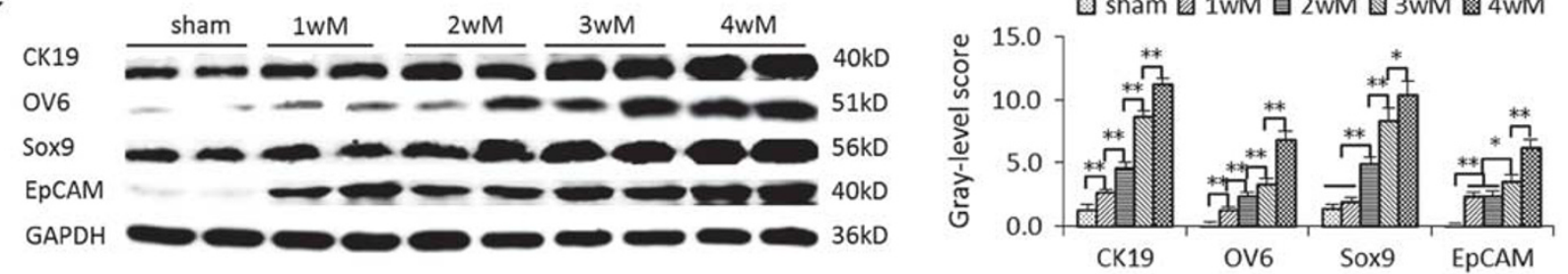

f

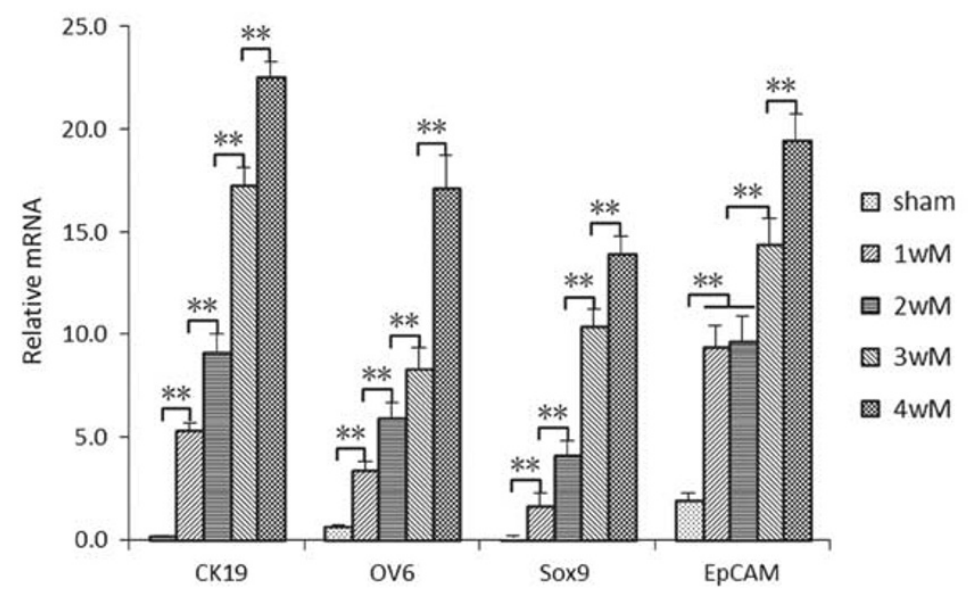

Figure 2 HPCs participated in bile duct proliferation in CLF. (a) CK19 immunostaining ( $\times 200)$. (b) OV6 immunostaining ( $\times 200)$. (c) Double immunofluorescent staining of CK19 (red) and OV6 (green) merged ( $\times 200)$. (d) Double immunofluorescent staining of CK19 (red) and Sox9 (green) merged ( $\times 200)$. (e) CK19, OV6, Sox9, and EpCAM protein expression; bands are depicted in immunoblots and the histogram is a densitometric analysis of the protein bands ( $n=6$ per group). (f) CK7, CK19, OV6, Sox9, and EpCam mRNA normalized to GAPDH mRNA ( $n=6$ per group). ${ }^{*}<<0.05, * * P<0.01$. Sham, Sham group; 1 wM, BDL-1w group; 2 wM, BDL-2w group; 3 wM, BDL-3w group; 4 wM, BDL-4w group. 
a

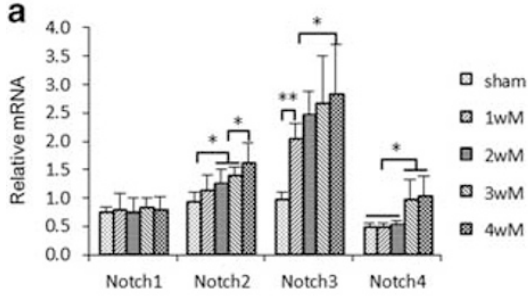

b
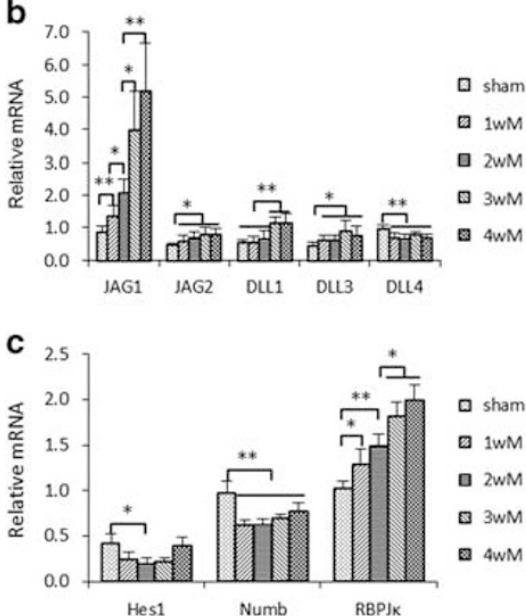

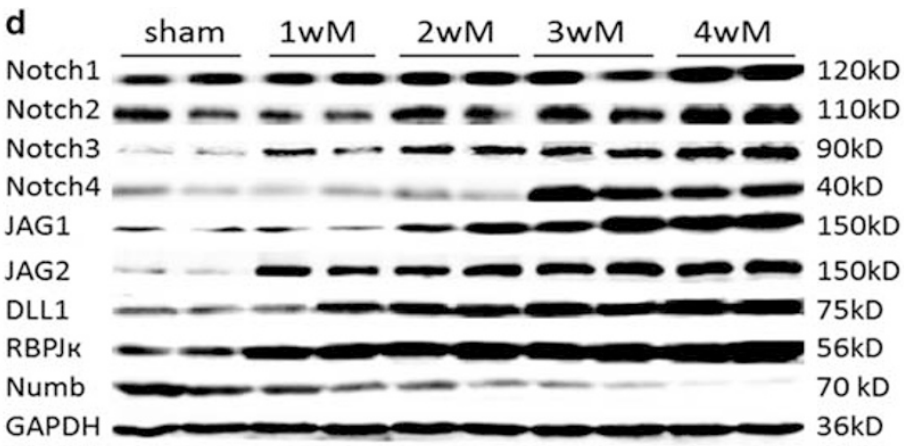

$\square$ sham $\square 1 \mathrm{WM} \square 2 \mathrm{WM} \square 3 \mathrm{WM} \square 4 \mathrm{WM}$

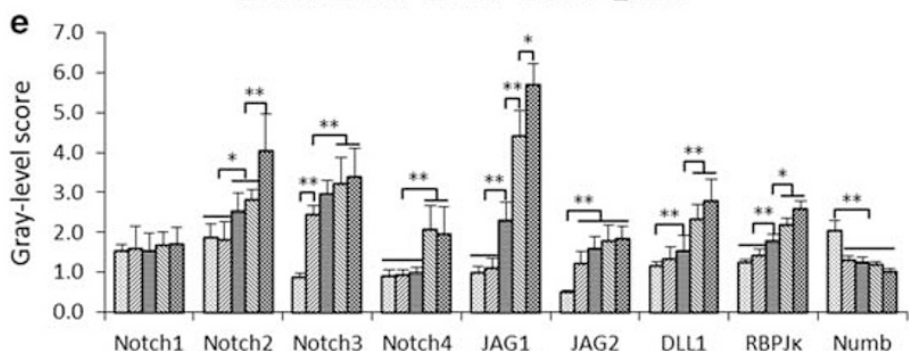

Figure 3 Notch signaling pathway was activated in CLF. (a) Notch-1, 2, 3, 4 mRNA. (b) JAG1, 2, and DLL1, 3, 4 mRNA. (c) Hes1, Numb, and RBPJK mRNA. All mRNA were quantified with RT-PCR and normalized to GAPDH mRNA ( $n=6$ per group). (d) Notch-1, Notch-2, Notch3, Notch4, JAG1, JAG2, DLL1, RBPJK, and Numb protein expression were quantified via immunoblotting and normalized to GAPDH ( $n=6$ per group), and (e) densitometric analysis of protein bands. ${ }^{*} P<0.05,{ }^{*} P<0.01$. Sham, Sham group; $1 \mathrm{wM}, \mathrm{BDL}-1 \mathrm{w}$ group; $2 \mathrm{wM}, \mathrm{BDL}-2 \mathrm{w}$ group; $3 \mathrm{wM}, \mathrm{BDL}-3 \mathrm{w}$ group; $4 \mathrm{wM}, \mathrm{BDL}-4 \mathrm{w}$ group.

\section{Notch Signaling Pathways Are Involved in Cholestatic Fibrogenesis}

Notch-2, -3, -4, Jagged-1, -2, Delta-1, -3 and RBP-J $\kappa$ mRNA, protein and fibrogenesis gradually increased compared with the sham group $(P<0.05$ or $P<0.01)$. However, Numb (a negative regulatory factor of Notch signaling) mRNA was decreased clearly at each time point in BDL-treated rats $(P<0.01$, Figures $3 \mathrm{a}$ and $\mathrm{e})$ and Numb protein was reduced significantly compared with the sham group the first week after BDL treatment $(P<0.01$, Figures $3 \mathrm{~d}$ and e). Therefore, the Notch signaling pathway was activated during CLF induced by BDL.

\section{Inhibition of Notch Signaling Reduced HPC Proliferation in CLF Induced by BDL}

Immunostaining confirmed that hepatic CK19 and OV6 expression increased in the BDL group and was greatly reduced after DAPT treatment (Figures $4 \mathrm{a}$ and b). Co-immunostaining revealed that Sox9/CK19 co-expression was clearly reduced after DAPT treatment (Figure 4c). In addition, CK19, OV6, Sox9, and EpCAM mRNA and protein increased significantly in the BDL group compared with the sham group $(P<0.01)$, and they decreased significantly after DAPT treatment compared with the BDL group $(P<0.01)$ (Figures $4 \mathrm{~d}-\mathrm{f}$ ). Thus, inhibition of Notch signaling reduced HPC proliferation.
When WB-F344 cells were treated with SB, CK19 was strongly expressed in the cytoplasm (Figure 5a), and CK19, Sox9, and EpCAM mRNA and protein increased significantly in the SB group compared with the control group $(P<0.01)$, but both mRNA and protein for these indicators were reduced by DAPT treatment $(P<0.01$, Figures $5 \mathrm{~b}-\mathrm{d})$. In addition, the Notch signaling compositions including Notch1, -3, JAG1, -2, -3, and HES1 mRNA expression were increased significantly in the SB group compared with the control group, and these were significantly decreased after DAPT treatment $(P<0.01$, Figure $5 e)$. Therefore, inhibition of Notch signaling reduces hepatic progenitor-cholangiocyte phenotype differentiation in vivo.

\section{Inhibition Notch Signaling Prevents Fibrotic Progression Induced by BDL}

To validate the role of Notch signaling in CLF, we combined DAPT with BDL for 2 weeks as described in the Materials and Methods (DAPT group). Data indicate that Notch-1, $-2,-3$, -4 , JAG1, -2 , DLL1, and RBP-J $\kappa$ protein and mRNA was decreased significantly in the DAPT group compared with BDL group $(P<0.01)$ (Figures $6 \mathrm{a}$ and $\mathrm{b})$. However, Numb protein and mRNA did not change after DAPT treatment $(P>0.05)$.

Inhibition of Notch signaling reduced collagen deposition and $\alpha$-SMA expression (Figures $6 \mathrm{c}$ and $\mathrm{d}$ ), and HYP 

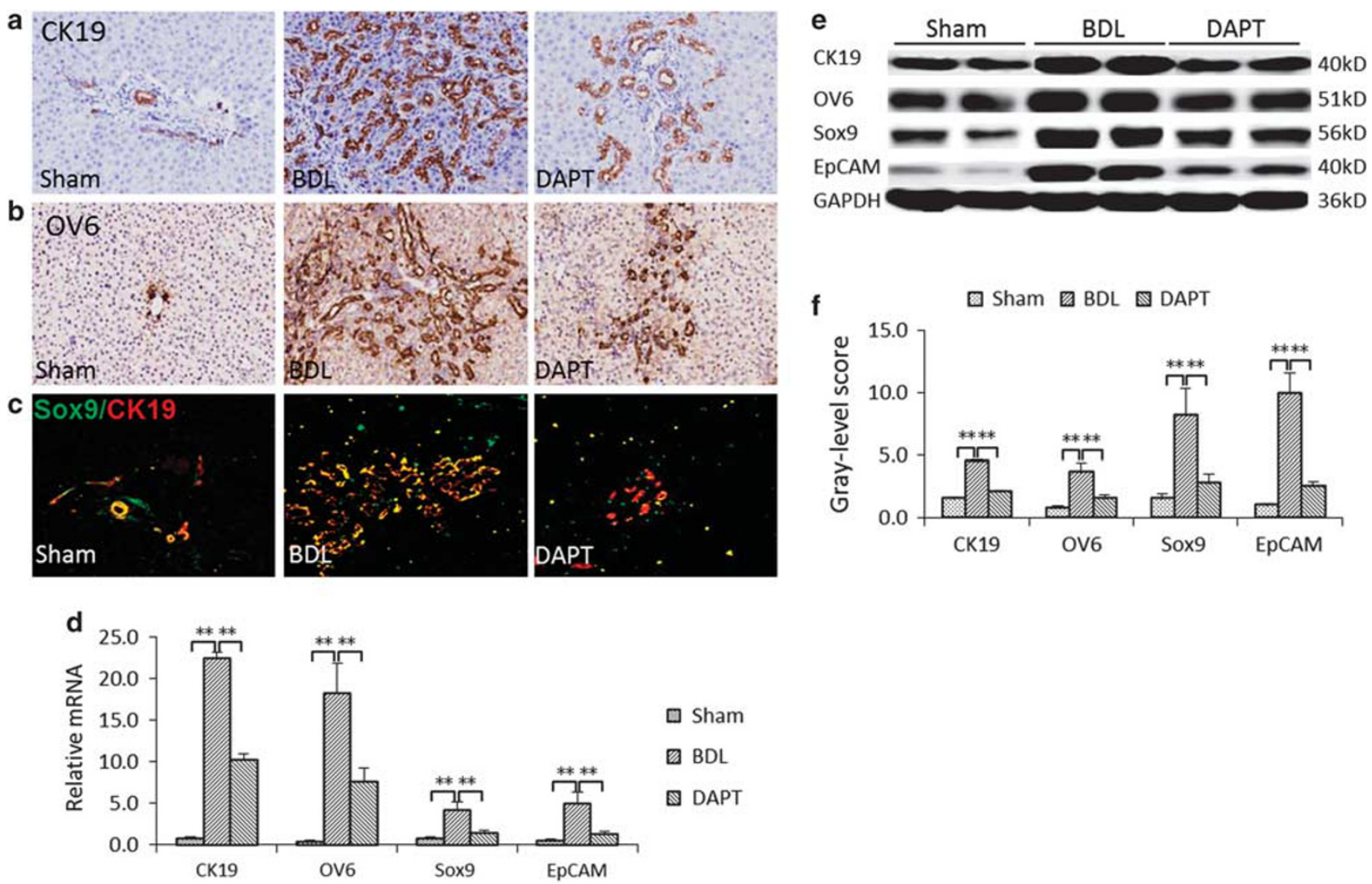

Figure 4 Inhibition of Notch signaling reduced HPC differentiation to bile duct epithelial cells in vivo. (a) Immunostaining of CK19 ( $\times 200)$. (b) Immunostaining of OV6 (×200). (c) Double immunofluorescent staining of CK19 (red) and Sox9 (green) merged (×200). (d) CK19, OV6, Sox9, and EpCAM mRNA were measured with RT-PCR and normalized to GAPDH mRNA ( $n=6$ per group). (e) CK19, OV6, Sox9, and EpCAM protein were quantified with immunoblotting, and (f) densitometric analysis of protein bands normalized to GAPDH ( $n=6$ per group). ${ }^{*} P<0.05$, ${ }^{* *} P<0.01$. BDL, single bile duct ligation group; DAPT, BDL plus DAPT group; sham, sham group.

decreased significantly in the DAPT group compared with the BDL group $(P<0.05$, Figure 6e). $\alpha$-SMA, TNF- $\alpha$, TGF- $\beta 1$, MCP-1, $\operatorname{Col}(1)$, and $\operatorname{Col}(4)$ mRNA decreased significantly in the DAPT group compared with the BDL group $(P<0.05$, Figure 6f). Therefore, inhibition of Notch signaling prevents fibrogenesis induced by BDL.

\section{DISCUSSION}

Hepatic fibrosis induced by BDL is unique in that the primary pathological lesions occur in the area surrounding the bile duct epithelium. The BDL procedure introduces biomechanical stress to the biliary epithelium and initially triggers compensatory proliferation and expansion of BECs. ${ }^{27,28}$ This pathological change is referred to as a 'bile duct reaction' or 'reactive bile duct epithelial cells'. ${ }^{29}$ Proliferated BECs can secrete a variety of profibrotic cytokines, which promote the activation and proliferation of MFs and HSCs, and promote the synthesis of an excessive ECM, thereby initiating the development of CLF. ${ }^{2}$

Stem cells undergo self-renewal and differentiate into potential cell populations. It has been established that a bipotential cell type with stem cell properties exists in the adult liver and can differentiate into both hepatocytes and cholangiocytes, cells that are referred to as oval cells or HPCs. ${ }^{20,30}$ In 3,5-diethoxycarbonyl-1,4-dihydrocollidine (DDC) and alpha-naphthyl-isothiocyanate (ANIT)-induced mouse models of biliary damage, HPCs participate in the repair of the bile duct. A lack of Notch-2 receptors (Notch-2cKO) prevents biliary tubule formation, both in vivo and in vitro, and a lack of RBP-Jk inhibits the generation of biliary-committed precursors and tubule formation. ${ }^{8}$

In the present study, after bile duct ligation, mRNA and protein expression of BEC markers CK19, and HPC markers OV6, Sox9, and EpCAM were significantly higher and were correlated with the progression of liver fibrosis. Co-Immunostaining showed that OV6 and CK19, Sox9, and CK19 are widely co-expressed in proliferating BECs. Therefore HPCs are involved in the pathological process of a ductular reaction. To prove the potential of HPC-cholangiocyte differentiation, our in vitro experiments confirmed that sodium butyrate induced WB-F344 cells to differentiate into a cholangiocyte phenotype, and CK19-positive staining cells were significantly increased. mRNA and protein expression of CK19, Sox9, and EpCAM increased significantly, too. 

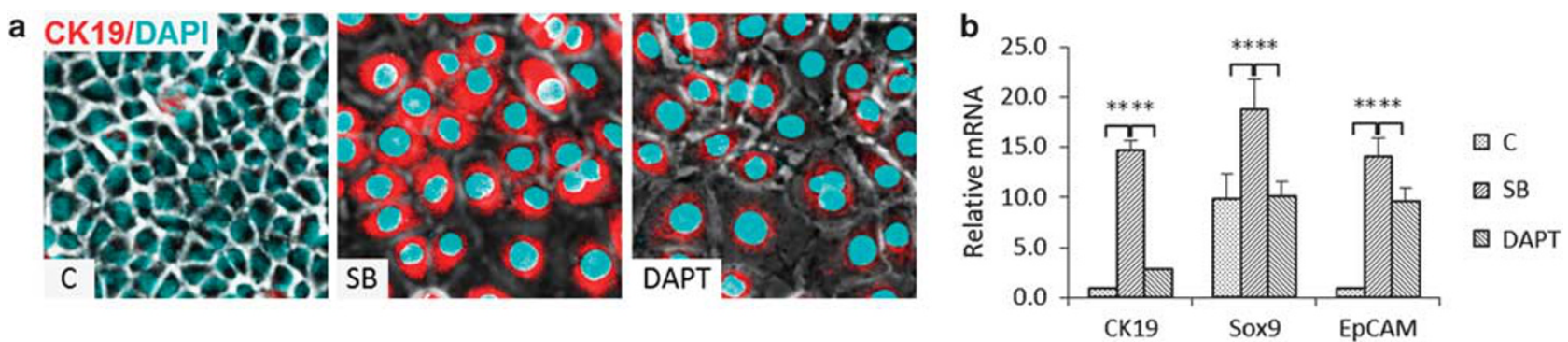

C

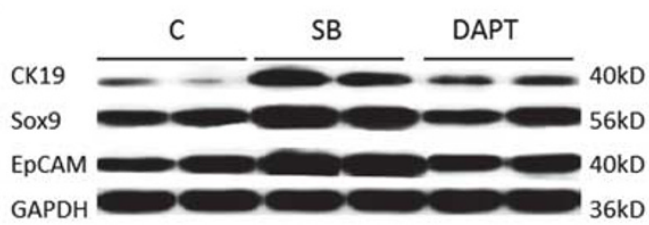

e
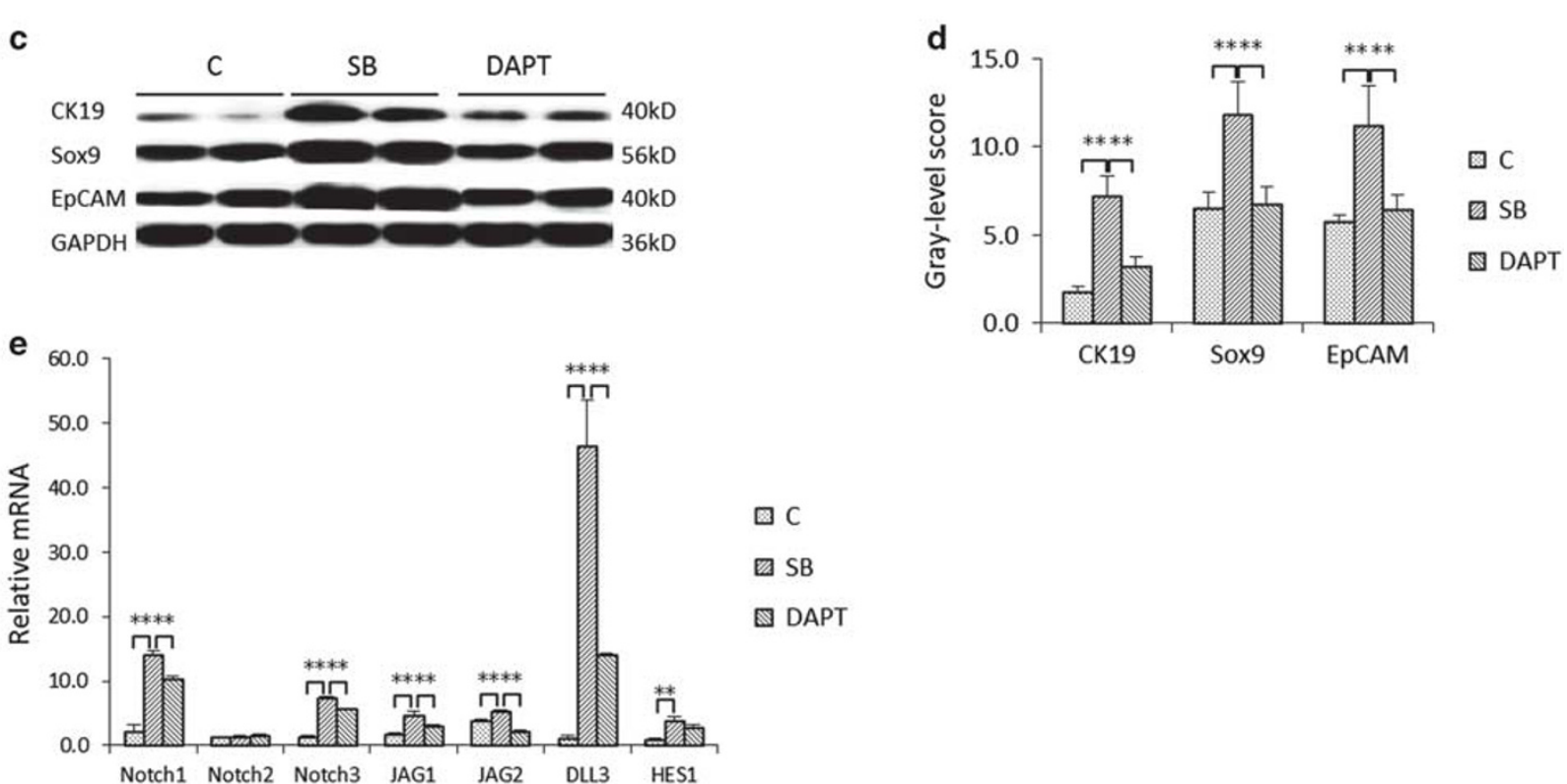

Figure 5 Inhibition of Notch signaling reduced HPC differentiation to bile duct epithelial cells in vitro. (a) Immunofluorescent staining of CK19 (red) and DAPI (blue) ( $\times 400)$. (b) CK19, Sox9, and EpCAM mRNA were measured with RT-PCR and normalized to GAPDH mRNA ( $n=6$ per group). (c) CK19, Sox9, and EpCAM protein was quantified by immunoblotting and normalized to GAPDH, and (d) densitometric analysis of protein bands ( $n=6$ per group). (e) Notch1, Notch2, Notch3, JAG1, JAG2, DLL3 and HES1 mRNA were measured with RT-PCR and normalized to GAPDH mRNA ( $n=6$ per group). ${ }^{*} P<0.05$, ${ }^{*} P<0.01$. C, control group; DAPT, SB plus DAPT ( $\left.25 \mu \mathrm{M}\right)$ group; SB, sodium butyrate group (3.75 mM).

Therefore, HPCs are chief source of proliferating cholangiocytes in cholestatic fibrosis.

In addition, Notch signaling is an evolutionarily conserved intercellular signaling pathway required for cell specification, lineage commitment, and maintenance of stem/progenitor cells during development and in adults. ${ }^{31}$ The Notch signaling pathway determines the density of 3D peripheral intrahepatic bile duct architecture ${ }^{15}$ and it is necessary for specification of the biliary tree. Notch pathway ablation results in failure of hepatoblast specification into cholangiocytes, resulting in bile duct paucity, ${ }^{12,30}$ which is a characteristic of Alagilles syndrome. ${ }^{14}$ During chronic injury, a population of bipotent HPCs becomes activated to regenerate both cholangiocytes and hepatocytes. During hepatocyte regeneration, hepatocellular specification of HPCs is determined by the release of Wnt3a by macrophages after phagocytosis of cellular debris from damaged hepatocytes. During biliary regeneration, expression of JAG1 (a Notch ligand) by MFs promotes Notch signaling in HPCs and thus their biliary specification to cholangiocytes. ${ }^{30}$ Numb is a cell-fate determinant that is localized to endosomes, controlling cell-fate choices by asymmetrically partitioning at mitosis and antagonizing Notch family plasma membrane receptor activity. ${ }^{32-34}$

According to our results, Notch receptors Notch-2, -3, -4, and Notch ligand Jagged-1, -2, Deltal-3, as well as RBP-J $\kappa$ mRNA and protein expression significantly increased after BDL. So, Notch signaling enhanced bile duct proliferation. To confirm whether Notch signaling has a critical role in CLF, we repeated the experiments with BDL rats and added DAPT and observed that DAPT inhibited the activation of Notch signaling, and that cholangiocyte proliferation was significantly reduced. OV6, SOX9, and EpCAM expression was also decreased significantly, and consequently, the degree of liver fibrosis was significantly reduced. SB treatment of WB-F344 cell lines promoted their differentiation into a cholangiocyte phenotype, and DAPT intervention significantly inhibited this process. Therefore, Notch signaling is needed for fibrogenesis induced by BDL in rats, and this may occur via enhanced HPC differentiation into cholangiocytes.

In summary, in BDL-induced liver fibrosis, HPCs are a source of proliferating BECs, and Notch signaling promotes the differentiation of HPCs to BECs. Thus, blocking Notch 
a

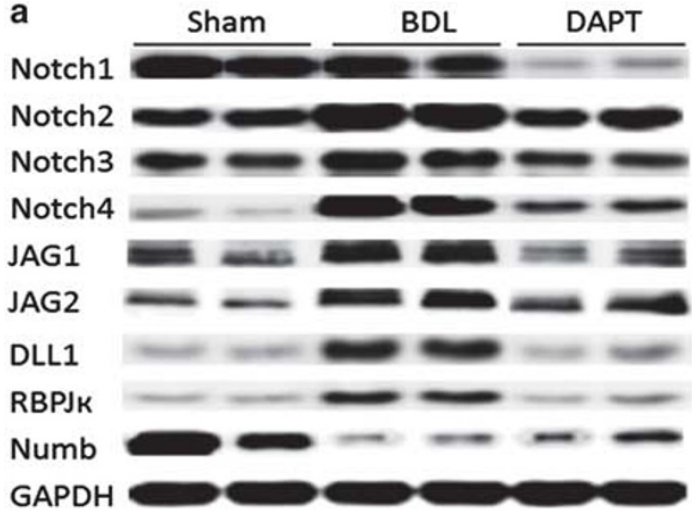

b

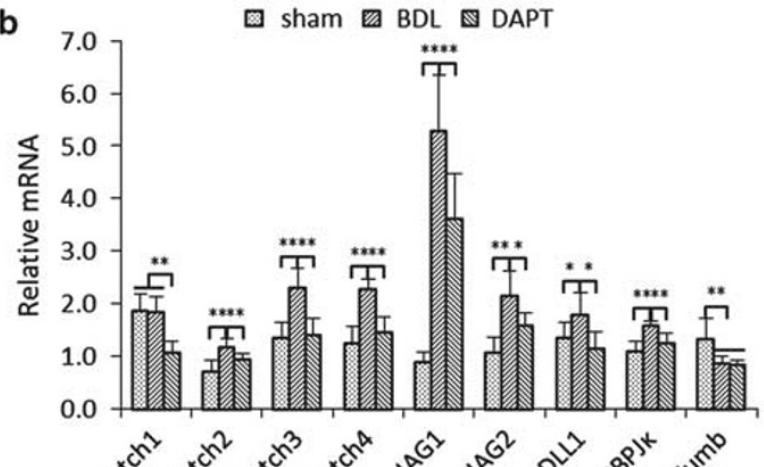

120kD

$110 \mathrm{kD}$

90kD

40kD

$150 \mathrm{kD}$

150kD

$75 \mathrm{kD}$

$56 \mathrm{kD}$

$70 \mathrm{kD}$

$36 \mathrm{kD}$

\section{C}

Sirius Red
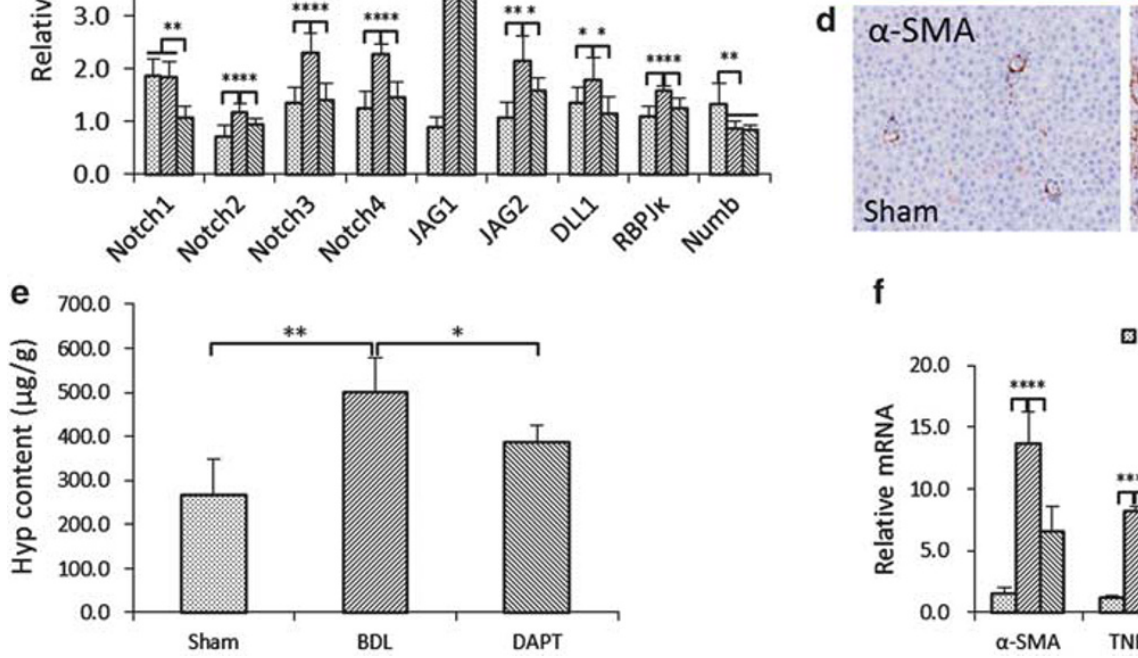

f
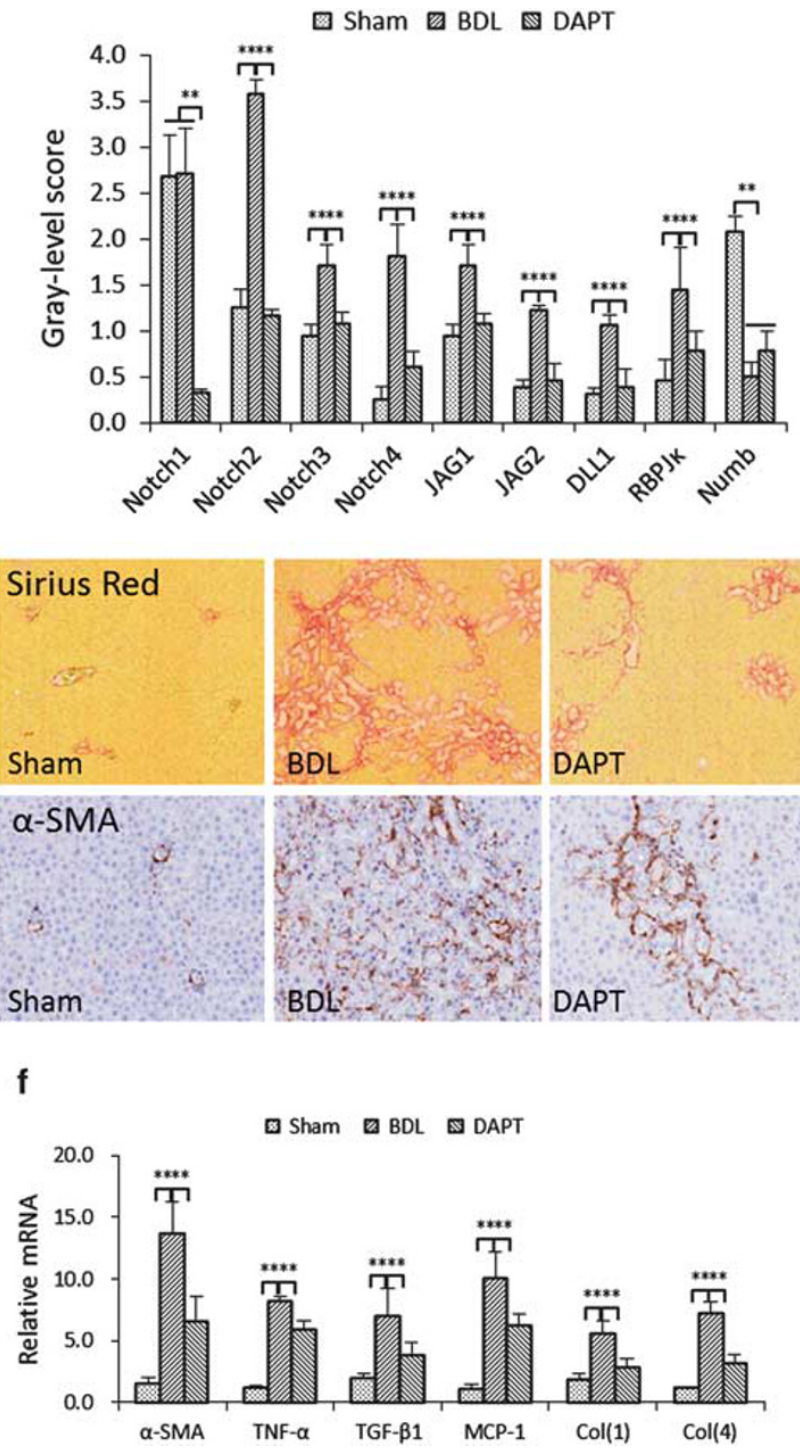

Figure 6 Inhibition of the Notch signaling pathway reduced the progression of liver fibrosis. (a) Notch-1, Notch-2, Notch3, Notch4, JAG1, JAG2, DLL1, RBPJK, and Numb, protein bands on the left (immunoblot), and the histogram depicts the densitometric analysis of protein bands ( $n=6$ per group). (b) Notch-1, Notch-2, Notch3, Notch4, JAG1, JAG2, DLL1, RBPJK, and Numb mRNA were measured via RT-PCR and normalized to GAPDH mRNA ( $n=6$ per group). (c) Sirius Red staining (×100). (d) $a$-SMA immunostaining ( $\times 200)$. (e) Hydroxyproline content. (f) $a-$ SMA, TNF- $\alpha$, TGF- $\beta 1$, MCP-1, Col(1), and Col (4) mRNA were measured by RT-PCR and normalized to GAPDH mRNA ( $n=6$ per group). ${ }^{*} P<0.05,{ }^{*} P<0.01$. BDL, single bile duct ligation group; DAPT, BDL plus DAPT group; sham, sham group.

signaling can suppress this process, inhibiting the progression of liver fibrosis. This may be a therapeutic pathway for treating cholestatic liver disease in humans. Also, Numb may be important to CLF but more work is required to establish an interaction between fibrogenesis and Numb in this disease.

Supplementary Information accompanies the paper on the Laboratory Investigation website (http://www.laboratoryinvestigation.org)

\section{ACKNOWLEDGMENTS}

This study was supported by the National Natural Science Foundation of China (2011, No. 81173223), and by the National Natural Science Foundation of China (2012, No. 81273728).

\section{DISCLOSURE/CONFLICT OF INTEREST}

The authors declare no conflict of interest.

1. Guicciardi ME, Gores GJ. Bile acid-mediated hepatocyte apoptosis and cholestatic liver disease. Dig Liver Dis 2002;34:387-392.

2. Matsumoto K, Fujii $\mathrm{H}$, Michalopoulos $\mathrm{G}$ et al. Human biliary epithelial cells secrete and respond to cytokines and hepatocyte growth factors in vitro: Interleukin-6, hepatocyte growth factor and epidermal growth factor promote DNA synthesis in vitro. Hepatology 1994;20:376-382.

3. Marra F, DeFranco R, Grappone C et al. Increased expression of monocyte chemotactic protein-1 during active hepatic fibrogenesis Correlation with monocyte infiltration. Am J Pathol 1998:152:423-430.

4. Harada K, Chiba M, Okamura A et al. Monocyte chemoattractant protein-1 derived from biliary innate immunity contributes to hepatic fibrogenesis. J Clin Pathol 2011;64:660-665. 
5. Sedlaczek N, Jia JD, Bauer M et al. Proliferating bile duct epithelial cells are a major source of connective tissue growth factor in rat biliary fibrosis. Am J Pathol 2001;158:1239-1244.

6. Park SM. The crucial role of cholangiocytes in cholangiopathies. Gut Liver 2012;6:295-304.

7. Momah N, Lindor KD. Primary biliary cirrhosis in adults. Expert Rev Gastroenterol Hepatol 2014;8:427-433.

8. Fiorotto R, Raizner A, Morell CM et al. Notch signaling regulates tubular morphogenesis during repair from biliary damage in mice. J Hepatol 2013;59:124-130.

9. Flynn DM, Nijjar S, Hubscher SG et al. The role of Notch receptor expression in bile duct development and disease. J Pathol 2004;204: 55-64.

10. Kopan R, llagan MX. The canonical Notch signaling pathway: unfoldingthe activation mechanism. Cell 2009;137:216-233.

11. Lozier J, McCright B, Gridley T. Notch signaling regulates bile duct morphogenesis in mice. PLoS One 2008;3:e1851.

12. McCright B, Lozier J, Gridley T. A mouse model of Alagille syndrome: Notch2 as a genetic modifier of Jag1 haploinsufficiency. Development 2002;129:1075-1082.

13. Oda T, Elkahloun AG, Pike BL et al. Mutations in the human Jagged 1 gene are responsible for Alagille syndrome. Nat Genet 1997;16: 235-242.

14. Li L, Krantz ID, Deng $Y$ et al. Alagille syndrome is caused by mutations in human Jagged1, which encodes a ligand for Notch1. Nat Genet 1997;16:243-251.

15. Sparks EE, Huppert KA, Brown MA et al. Notch signaling regulates formation of the three-dimensional architecture of intrahepatic bile ducts in mice. Hepatology 2010;51:1391-1400.

16. Kamiya A, Kakinuma S, Yamazaki $Y$ et al. Enrichment and clonal culture of progenitor cells during mouse postnatal liver development in mice. Gastroenterology 2009;137:1114-1126.

17. Alpini G, Lenzi R, Sarkozi L et al. Biliary physiology in rats with bile ductular cell hyperplasia. Evidence for a secretory function of proliferated bile ductules. J Clin Invest 1988;81:569-578.

18. Jamall IS, Finelli VN, Que SS. A simple method to determine nanogram levels of 4-hydroyproline in biological tissues. Anal Biochem 1981;112: 70-75.

19. Mu YP, Ogawa T, Kawada N. Reversibility of fibrosis, inflammation, and endoplasmic reticulum stress in the liver of rats fed a methioninecholine-deficient diet. Lab Invest 2010;90:245-256.
20. Tsao MS, Smith JD, Nelson KG et al. A diploid epithelial cell line from normal adult rat liver with phenotypic properties of 'oval' cells. Exp Cell Res 1984;154:38-52.

21. Couchie D, Holic N, Chobert MN et al. In vitro differentiation of WBF344 rat liver epithelial cells into the biliary lineage. Differentiation 2002;69:209-215.

22. Mishra L, Banker T, Murray J et al. Liver stem cells and hepatocellular carcinoma. Hepatology 2009;49:318-329.

23. Crosby HA, Hubscher SG, Joplin RE et al. Immunolocalization of OV-6, a putative progenitor cell marker in human fetal and diseased pediatric liver. Hepatology 1998;28:980-985.

24. Cardinale V, Wang Y, Carpino G et al. Multipotent stem/progenitor cells in human biliary tree give rise to hepatocytes, cholangiocytes, and pancreatic islets. Hepatology 2011;54:2159-2172.

25. Tarlow BD, Finegold MJ, Grompe M. Clonal tracing of Sox9+ liver progenitors in mouse oval cell injury. Hepatology 2014;60: 278-289.

26. Hao PP, Lee MJ, Yu GR et al. Isolation of EpCAM(+)/CD133 (-) hepatic progenitor cells. Mol Cells 2013;36:424-431.

27. Ezure T, Sakamoto T, Tsuji $\mathrm{H}$ et al. The development and compensation of biliary cirrhosis in interleukin-6-deficient mice. Am J Pathol 2000;156:1627-1639.

28. Lunz 3rd JG , Contrucci S, Ruppert K et al. Replicative senescence of biliary epithelial cells precedes bile duct loss in chronic liver allograft rejection: increased expression of p21(WAF1/Cip1) as a disease marker and the influence of immunosuppressive drugs. Am J Pathol 2001;158: 1379-1390.

29. Choi SS, Diehl AM. Epithelial-to-mesenchymal transitions in the liver. Hepatology 2009;50:2007-2013.

30. Boulter L, Govaere O, Bird TG et al. Macrophage-derived Wnt opposes Notch signaling to specify hepatic progenitor cell fate in chronic liver disease. Nat Med 2012;18:572-579.

31. Chiba S. Notch signaling in stem cell systems. Stem Cells 2006;24: 2437-2447.

32. Roegiers F, Jan YN. Asymmetric cell division. Curr Opin Cell Biol 2004;16:195-205.

33. Couturier L, Mazouni K, Schweisguth F. Numb localizes at endosomes and controls the endosomal sorting of notch after asymmetric division in Drosophila. Curr Biol 2013;23:588-593.

34. Couturier L, Vodovar N, Schweisguth F. Endocytosis by Numb breaks Notch symmetry at cytokinesis. Nat Cell Biol 2012;14:131-139. 